\title{
A Rare Case of Secondary Abdominal Pregnancy
}

\author{
Dr. Aparna BL ${ }^{1}$, Dr. Shalini $B^{2}$, Dr. Priyadarshani $D^{3}$, Dr. Romita $N^{4}$, Dr. Ranjit Singh $L^{5}$ \\ ${ }^{1,2,3}$ PGT, RIMS Imphal \\ ${ }^{4}$ Senior Resident, RIMS Imphal \\ ${ }^{5}$ Head of Obs and Gynae Department, RIMS ,Imphal
}

\begin{abstract}
We report a case of second gravida with one living issue with undiagnosed secondary abdominal pregnancy admitted in our hospital in shock. Screening USG showed a normal uterus with a live fetus of 16 week 2 days gestation lying in abdominal cavity. Emergency laparotomy done with extraction of fetus and placenta with left salpingectomy, with left partial oophorectomy, with left partial omentectomy. Beta HCG returned to normal after 3 weeks with complete resorption of placenta in USG in one month. This case stresses the importance of regular ante natal check up with early diagnosis and prompt management of abdominal pregnancy which otherwise may lead to maternal morbidity and mortality.
\end{abstract}

Keywords: Abdominal pregnancy, Shock, Emergency laparotomy, Beta HCG

\section{Introduction}

Abdominal pregnancy is an implantation in the peritoneal cavity exclusive of tubal, ovarian, or intraligamentous implantations ${ }^{1}$. These are rare ectopic pregnancies with an estimated incidence of 1 in 10,000 to 25,000 live births. The overall mortality rate associated with abdominal pregnancy is 0.5 to $8.0 \% \%^{2}$. Delay in diagnosis is mainly due to difficulties in clinical assessment caused by variance in presentations. The treatment of secondary abdominal pregnancy is ultimately surgical. The surgical management of attached portions of placenta will always represent the major problem.

\section{Case Report}

A 35 year old woman, $2^{\text {nd }}$ gravid with one previous full term vaginal delivery at home 2 years back with unknown LMP, 3 months amenorrhea without any antenatal check up admitted on 15/9/15 with complaints of severe abdominal pain. The pain started 5 days back which increased in severity and associated with generalized weakness. On admission she had moderate anemia, tachycardia and hypotension. Abdominal examination revealed tenderness and guarding. Per vaginal examination revealed normal sized uterus and ill defined mass in left adnexa. Screening USG done showed normal uterus with a live fetus of 16 weeks 2 days gestation lying in abdominal cavity, placenta seen anteriorly and above fundus and no myometrium defined around fetus and placenta. A diagnosis of abdominal pregnancy was made with intra peritoneal collection. Emergency laparotomy was done. During surgery the fetus and gestational sac was seeing lying in abdominal cavity with placenta adherent to left fallopian tube, ovary and omentum (Fig1). Torrential bleeding was present. Extraction of fetus with placental removal with left salpingectomy with left partial oophorectomy with partial omentectomy was done and part of placenta was left behind as it was not safe to remove. Around 2 liter of blood loss determined and 2 unit of packed RBC transfused intra operatively and 3 units post operatively. Post operative period was uneventful with removal of drain on day 2 with minimal collection. Patient discharged on post op day 7 with hemoglobin 9.6. Serum beta HCG returned to normal after 3 weeks and USG revealed complete resorption of placenta after 1 month follow up.

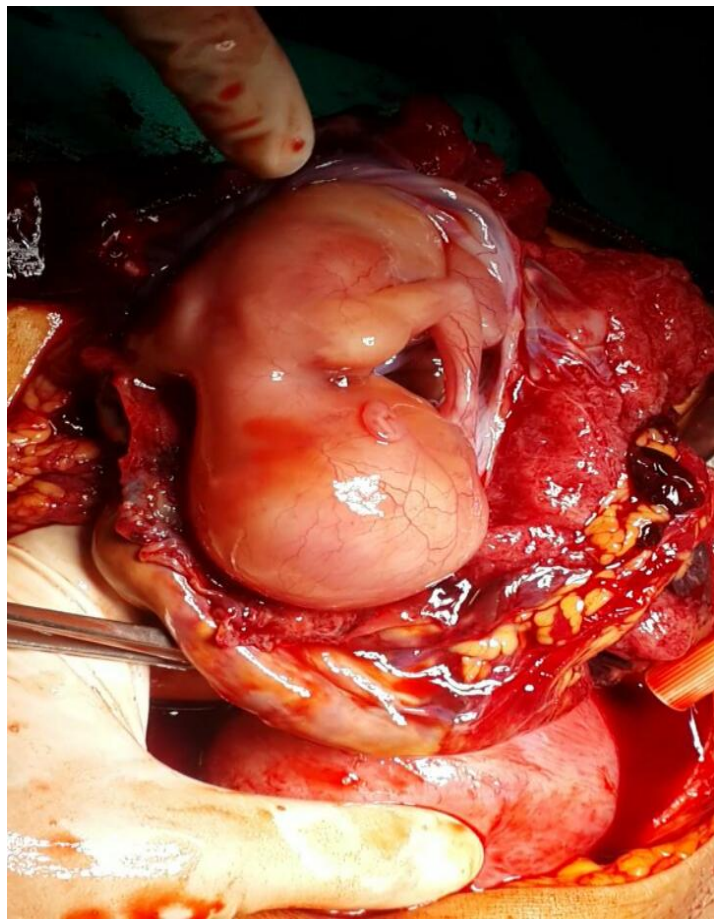

Figure 1:

\section{Discussion}

Abdominal pregnancies are classified as primary and secondary. Most of them are secondary the result of early tubal abortion or rupture with secondary implantation of the pregnancy into peritoneal cavity.

Diagnosis may be difficult. First, symptoms may be absent or vague. Laboratory tests are typically uninformative, although maternal serum alpha-fetoprotein levels may be elevated. Clinically, abnormal fetal positions may be palpated, or the cervix is displaced ${ }^{3}$. Sonographically, findings with an abdominal pregnancy may not be recognized, and the diagnosis is often missed ${ }^{4}$. Even then

\section{Volume 4 Issue 11, November 2015}




\section{International Journal of Science and Research (IJSR) \\ ISSN (Online): 2319-7064}

Index Copernicus Value (2013): 6.14 | Impact Factor (2014): 5.611

ultrasound is the most effective method for diagnosing an abdominal pregnancy. The area of implantation of the placenta and its relationship to the pelvic organs and the vascular supply could be more closely visualized by MRI.

An abdominal pregnancy can be life-threatening, and management depends on the gestational age at diagnosis. Some describe waiting until fetal viability with close surveillance $^{5,6}$. Of note, reported fetal malformations and deformations in 20 percent $^{7}$. The most common malformations were limb deficiency and central nervous system anomalies. The most common deformations were facial and/or cranial asymmetry and various joint abnormalities. Conservative management also carries a maternal risk for sudden and dangerous hemorrhage. We are of the opinion that termination generally is indicated when the diagnosis is made. Certainly, before 24 weeks, conservative treatment rarely is justified.

The principal surgical objectives involve delivery of the fetus and careful assessment of placental implantation without provoking hemorrhage. Unnecessary exploration is avoided because the anatomy is commonly distorted and surrounding areas will be extremely vascular.

\section{Conclusion}

Such pregnancy can be life threatening so this case stresses upon the need of early and regular antenatal checkups, so that such cases can be managed in a better way with proper operative techniques and multidisciplinary surgical team resulting in reduction in maternal morbidity and mortality.

\section{References}

[1] F. Gary Cunningham, Kenneth J. Leveno, Steven L. Bloom, Catherine Y. Spong, Jodi S. Dashe, Barbara L. Hoffman et al, Williams obstretics $24^{\text {th }}$ edition, McGrawHill Education, New York, 2014

[2] B. R. Desai, S. Shobhana, V. Pujar Yeshita, "Advanced secondary abdominal pregnancy following rupture of rudimentary horn," Journal of Obstetrics and Gynecology India, 55(2), pp.180, March/April 2005.

[3] W. Zeck, I. Kelters, R Winter, "Lessons learned from four advanced abdominal pregnancies at an East African Health Center," Jornal of Perinatal Medicine, 35(4), pp.278, 2007.

[4] S. D. Costa, J. Presley, G. Bastert, "Advanced abdominal pregnancy," Obstetrical and gynecological survey, 46, pp. 515,1991

[5] E. Gomez, L. Vergara, C. Weber, "Successful expectant management of an abdominal pregnancy diagnosed at 14 weeks," Journal of Maternal Fetal and Neonatal Medicine, 21(12), pp.917, 2008

[6] R. Varma, L. Mascarenhas , D. James, "Successful outcome of advanced abdominal pregnancy with exclusive omental insertion," Ultrasound in Obstetrics and Gynecology 12, pp.192, 2003

[7] C.A. Stevens, "Malformations and deformations in abdominal pregnancy," American Jornal of Medical Genetics, 47, pp.1189, 1993.

\section{Author Profile}

Dr. Aparna BL is PGT, Department of OBS and Gynae, RIMS, Imphal. 